J. Lake Sci.(湖泊科学), 2009, 21(3): 408-414

http://www.jlakes.org. E-mail: jlakes@niglas.ac.cn

(C)2009 by Journal of Lake Sciences

\title{
抚仙湖浮游甲壳动物群落结构与空间分布*
}

\author{
潘继征 ${ }^{1,3}$, 熊 飞 ${ }^{2}$, 李文朝 ${ }^{1}$, 李爱权 ${ }^{4}$ \\ (1: 中国科学院南京地理与湖泊研究所湖泊与环境国家重点实验室, 南京 210008) \\ (2: 江汉大学, 武汉 430056) \\ (3: 中国科学院研究生院, 北京 100049) \\ (4: 常州市环境保护研究所, 常州 213022)
}

摘 要: 云南抚仙湖是我国典型的高原深水湖泊, 为揭示湖中浮游甲壳动物对生态系统变化的响应, 研究了其群落结构与空 间分布特征. 2005 年 6-7 月在抚仙湖共采集浮游甲壳动物 8 种, 平均密度为 27.6ind./L, 优势类群为桡足类. 桡足类优势种为 舌状叶镖水蚤(Phyllodiaptomus tunguidus Shen et Tai), 枝角类优势种为角突网纹溞(Ceriodaphnia cornuta Sars)和象鼻溞 (Bosmina sp.). 浮游甲壳动物主要分布在 0-30m 水层, 密度随水深增加而下降; 0-10m 水层, 枝角类和无节幼体占优势, 大于 $10 \mathrm{~m}$ 水层, 桡足类占优势. 浮游甲壳动物密度南区大于北区 $(P<0.01)$, 而沿岸区与湖心区之间、沉水植物区与非沉水植物区之 间无显著性差异 $(P>0.05)$. 相关分析表明: 浮游甲壳动物密度的垂直分布与藻类密度和水体理化因子相关关系显著, 而水平 分布与藻类密度和水体理化因子相关关系不显著. 与 20 世纪 80 年代相比, 抚仙湖浮游甲壳动物优势种发生了演替, 西南荡镖 水蚤(Neutrodiaptomus mariadviagae mariadviagae (Brohm))消失, 被舌状叶镖水蚤代替, 可能与太湖新银鱼 (Neosalanx taihuensi Chen)引人有关; 浮游甲壳动物密度表现出增加趋势, 但仍处于较低水平, 与水体营养水平的提高及太湖新银鱼的捕 食压力有关

关键词: 浮游甲壳动物; 群落结构; 空间分布; 抚仙湖

\section{Community structure and spatial distribution of crustacean zooplankton in Lake Fuxian,} Yunnan, China

\section{PAN Jizheng ${ }^{1,3}$, XIONG Fei ${ }^{2}$, LI Wenchao ${ }^{1} \&$ LI Aiquan ${ }^{4}$}

(1: State Key Laboratory of Lake Science and Environment, Nanjing Institute of Geography and Limnology, Chinese Academy of Sciences, Nanjing 210008, P.R.China)

(2: Jianghan University, Wuhan 430056, P.R.China)

(3: Graduate School of Chinese Academy of Sciences, Beijing 100049, P.R.China)

(4: Changzhou Institute for Environmental Protection, Changzhou 213022, P.R.China)

Abstract: Lake Fuxian is a representative deep plateau lake located in Yunnan Province, China. To describe crustacean zooplankton's responses to ecological changes, we carried out studies on its community structure and spatial distribution. Altogether 8 taxa of crustacean zooplankton were founded in Lake Fuxian from June to July in 2005, and the average community density 27.6ind./L dominated by Copepoda. Dominant species of Copepoda were Phyllodiaptomus tunguidus Shen et Tai, and dominant species of cladoceran were Ceriodaphnia cornuta Sars and Bosmina sp. Crustacean zooplankton was mainly distributed from surface to 30m vertically, and its density decreased with the depth increase. Cladocera and Nauplii had the dominance in 0-10m layer, but Copepoda had the dominance when depth down to $10 \mathrm{~m}$. Average density of crustacean zooplankton was significantly higher in south lake than north lake $(P<0.01)$, while there were no significant differences in average density between near shore region and open water region,

\footnotetext{
* 湖泊与环境国家重点实验室开放基金资助. 2008-09-16 收稿; 2008-10-20 收修改稿. 潘继征, 男, 1975 年生, 助理研究员;
} E-mail: jzhpan@niglas.ac.cn. 
and between macrophyte distributed region and no macrophyte distributed region $(P>0.05)$. Correlation analysis indicated that there was significant correlation between the vertical density of crustacean zooplankton and algae density or water physical-chemical factors, but there was no significant correlation between the horizontal density and algae density or water physical-chemical factors. Compared with the surveys in 1980s, Neutrodiaptomus mariadviagae mariadviagae (Brohm), one of the dominant species of crustacean zooplankton, disappeared in the lake and was replaced by $P$. tunguidus, which was probably caused by introduction of Neosalanx taihuensi Chen. The density of crustacean zooplankton showed an increasing tendency, but that was still rather low, likely a result of increased nutrient levels and predation by $N$. taihuensi.

Keywords: Crustacean zooplankton; community structure; spatial distribution; Lake Fuxian

浮游甲壳动物主要包括桡足类和枝角类, 是水生生态系统的重要组成部分, 它们既是细菌和浮游植 物的牧食者, 又是鱼类的捕食对象. 随着水污染加剧, 湖泊生物多样性保护和富营养化防治面临着严峻 挑战, 浮游甲壳动物作为食物网中连接生产者和高级消费者的中间环节, 其群落生态学研究倍受关注. 目前对浮游甲壳动物的研究主要涉及群落结构 ${ }^{[1]}$ 、 时空动态及影响因子 ${ }^{[2-3]}$ 等多方面, 而群落长期演 替规律及其对环境变化和水体富营养化的响应是研 究焦点 ${ }^{[4-5]}$. 高原深水湖泊是我国一类特殊的湖泊 类群, 其浮游甲壳动物的生态研究还没有引起重视. 国外对深水湖泊浮游甲壳动物的研究较多 $[-7]$, 而国 内的研究主要集中在富营养化严重的浅水湖泊 ${ }^{[8-10]}$.

抚仙湖位于云南省玉溪市境内 $\left(24^{\circ} 21^{\prime} 28^{\prime \prime}\right.$ $-24^{\circ} 38^{\prime} 00^{\prime \prime} \mathrm{N}, 102^{\circ} 49^{\prime} 12^{\prime \prime}-102^{\circ} 57^{\prime} 26^{\prime \prime} \mathrm{E}$ ), 面积 $211 \mathrm{~km}^{2}$, 最大水深 $155 \mathrm{~m}$, 是我国高原深水湖泊的典型代表, 由于特殊的地理位置和独特的高原生境, 孕育了许 多特有物种, 在生物多样性研究和保护方面具有 重要价值. 关于湖中的浮游甲壳动物, 黎尚豪等 [11]、中国科学院南京地理与湖泊研究所 ${ }^{[12]}$ 曾对其 种类组成和群落结构做过一些调查. 自 20 世纪 80 年代中期以来, 抚仙湖浮游动物的研究基本是空 白. 而在这期间，随着太湖新银鱼等外来物种的 引人, 人湖污染负荷的加剧, 抚仙湖水体营养水 平逐渐提高, 透明度下降趋势明显 ${ }^{[13]}$, 生物类群 结构也发生了巨大变化 ${ }^{[14-16]}$, 势必会引起浮游甲 壳动物群落发生变化. 本文对抗仙湖浮游甲壳动 物的群落结构、空间分布及其与环境因子的关系进 行了研究, 旨在揭示抚仙湖浮游甲壳动物的长期 演变趋势及其对环境变化的响应, 为高原深水湖 泊生态系统长期变化研究积累资料.

\section{1 研究方法}

\section{1 样点设置}

2005 年 6-7 月, 依托抚仙湖高原深水湖泊生态 系统研究站的水上工作平台, 使用 NAVCOM SF-2050 导航定位, 对湖中浮游甲壳动物、藻类及相 关环境因子进行了调查, 根据抚仙湖的形态特点,

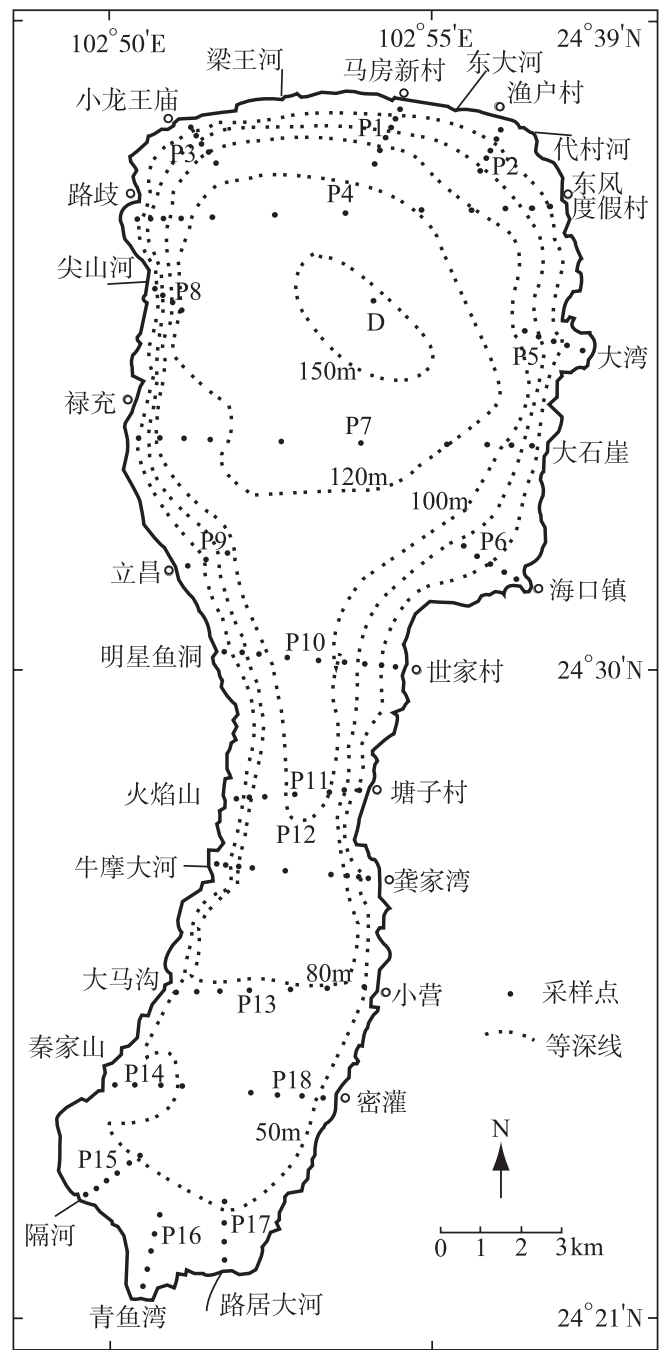

图 1 抚仙湖采样点分布

Fig.1 Distribution of sampling sites in Lake Fuxian 
全湖共设 18 个断面, 累计 110 个样点(图 1). 断面 P1-P9 位于北区, P10-P18 位于南区; 岸距 $<1000 \mathrm{~m}$ 的样 点归为沿岸区, 岸距 $\geqslant 1000 \mathrm{~m}$ 的样点归为湖心区. 在北部湖心区设 1 个垂向剖面 $\mathrm{D}\left(24^{\circ} 35^{\prime} 10^{\prime \prime} \mathrm{N}\right.$, $102^{\circ} 54^{\prime} 2^{\prime \prime} \mathrm{E}$ ), 水深 $154 \mathrm{~m}$, 每隔 $5 \mathrm{~m}$ 采样, 垂向采样进行 2 次, 取平均值.

\section{2 采样与分析}

用测绳和 RBR XR-620 深水水质剖面仪测量水深, 赛氏盘测量透明度(SD). 用 $25 \mathrm{~L}$ 柱状采水器采水, 水样为距表层 0.5-1.5m 的混和水样, 在水上工作平台上现场分样, 进行预处理. 取 0.5-2L 水样用于测定 叶绿素 a 浓度(Chl.a); 取 0.5-1L 水样经 $0.45 \mu \mathrm{m}$ 微孔滤膜过滤, 用于分析悬浮物(SS); 取 $1 \mathrm{~L}$ 水样用于测定 总氮 $(T N)$ 、总磷 $(\mathrm{TP}) 、$ 、溶解性总氮 $(\mathrm{DTN}) 、$ 、溶解性总磷 $(\mathrm{DTP})$; 取 $1 \mathrm{~L}$ 水样, 立即加 $15 \mathrm{ml}$ 鲁哥氏液固定, 作 为藻类定量样品; 取 $10 \mathrm{~L}$ 水样, 用 $64 \mu \mathrm{m}$ 浮游生物网过滤, $4 \%$ 福尔马林固定, 作为浮游甲壳动物的定量样 品. 湖心剖面及其它部分样点由 RBR XR-620 水质剖面仪获取温度、有效光合辐照度、 $\mathrm{pH}$ 值、溶解氧、 电导率、叶绿素 $\mathrm{a}$ 等垂向水质数据. 藻类和浮游甲壳动物种类的鉴定参考《淡水浮游生物研究方法》 ${ }^{[17]}$. 水质分析方法参考 《水和废水监测分析方法(第四版)》 ${ }^{[18]}$. 调查期间相关理化指标见表 1.

\section{3 数据处理}

数据的分析处理使用Excel和SPSS软件. 不同湖区之间密度比较使用 $t$ 检验, 密度与环境理化因子的 关系分析使用Pearson相关分析. 由于桡足类无节幼体的数量较多, 在计数时将无节幼体作为一类单独统 计. 文中出现的密度平均值为样点的算术平均值.

表 12005 年 6-7 月抚仙湖表层水体水质指标

Tab.1 Water quality indices of surface water in Lake Fuxian during June to July in 2005

\begin{tabular}{ccccccccc}
\hline 指标 & $\begin{array}{c}\mathrm{SD} \\
(\mathrm{m})\end{array}$ & $\begin{array}{c}\mathrm{SS} \\
(\mu \mathrm{g} / \mathrm{L})\end{array}$ & $\begin{array}{c}\mathrm{TN} \\
(\mu \mathrm{g} / \mathrm{L})\end{array}$ & $\begin{array}{c}\mathrm{DTN} \\
(\mu \mathrm{g} / \mathrm{L})\end{array}$ & $\begin{array}{c}\mathrm{TP} \\
(\mu \mathrm{g} / \mathrm{L})\end{array}$ & $\begin{array}{c}\text { DTP } \\
(\mu \mathrm{g} / \mathrm{L})\end{array}$ & $\begin{array}{c}\text { Chl.a } \\
(\mu \mathrm{g} / \mathrm{L})\end{array}$ & $\begin{array}{c}\text { 藻类 } \\
\left(\times 10^{4} \mathrm{ind} . / \mathrm{L}\right)\end{array}$ \\
\hline 平均值 & $4.00 \pm 1.23$ & $2.84 \pm 6.13$ & $0.44 \pm 0.47$ & $0.15 \pm 0.14$ & $0.02 \pm 0.03$ & $0.01 \pm 0.02$ & $2.27 \pm 2.89$ & $87.01 \pm 27.91$ \\
范围 & $0.50-6.20$ & $0.10-57.2$ & $0.09-1.95$ & $0.02-0.88$ & $0-0.15$ & $0-0.12$ & $0.22-25.71$ & $50.25-228.00$ \\
\hline
\end{tabular}

\section{2 研究结果}

\section{1 种类组成}

经鉴定, 共见到浮游甲壳动物 8 种(表 2), 其中桡足类 2 种, 包括舌状叶镖水蚤(Phyllodiaptomus tunguidus Shen et Tai)和剑水蚤(Cyclopoids); 枝角类 6 种, 包括角突网纹溞(Ceriodaphnia cornuta Sars)、象 鼻溞(Bosmina sp.)、长刺溞(Daphnia longispina (O. F. Müller))、矩形尖额溞(Alona rectangular Sars)、圆形 盘肠溞(Chydorus sphaericus (O. F. Müller))和秀体溞(Diaphanosoma sp.).

\section{2 密度和优势种}

浮游甲壳动物的出现率为 $98.2 \%$, 平均密度为 $27.6 \pm 65.5 i n d . / L$, 范围为 $0-449.5 i n d . / L$, 优势类群为桡 足类, 约占总密度的 $87 \%$, 其中无节幼体约占 $44 \%$. 各种类的密度和出现率见表 2. 桡足类(不含无节幼体) 优势种为舌状叶镖水蚤, 平均密度为 $11.4 i n d . / L$, 占桡足类密度的 $96.2 \%$. 枝角类优势种为角突网纹溞和 象鼻溞, 平均密度分别为 2.3ind./L 和 1.3ind./L，两者占总共枝角类密度的 $99.2 \%$.

\section{3 空间分布}

2.3.1 水平分布 抚仙湖不同断面浮游甲壳动物的密度分布见图 2. 在 18 个采样断面中, 抚仙湖最南端的 青鱼湾(P16 断面)浮游甲壳动物密度最高, 平均密度为 302.4ind./L, 范围为 227.0-449.5ind./L; 隔河口(P15) 次之, 平均密度为 75.4ind./L, 范围为 51.1-125.8ind./L; 北部湖区的路歧-东风度假村断面(P4)密度最低, 平均密度仅 1.08ind./L.

不同湖区浮游甲壳动物的密度比较见图 3. 南区平均密度为 $47.6 \pm 88.3 i n d . / L$, 明显大于北区的 7.6 $\pm 7.4 \mathrm{ind} . / \mathrm{L}(P<0.01)$, 南区的桡足类、无节幼体、枝角类密度分别为北区的 22.8 倍、4.9 倍和 1.9 倍(图 3a). 沿岸区和湖心区的平均密度分别为 $29.7 \pm 70.1$ ind./L、20.1 $445.8 \mathrm{ind} . / \mathrm{L}($ 图 3b), 但两者之间差异不显著 
$(P>0.05)$. 沉水植物区和非沉水植物区之间差异也不显著 $(P>0.05)$, 密度分别为 $21.9 \pm 46.8$ ind./L、 29.9 \pm 69.8ind./L; 枝角类密度在沉水植物区的密度略大, 而桡足类在非沉水植物区的密度偏大(图 3c).

表 2 抚仙湖浮游甲壳动物密度和出现率

Tab.2 Density and occurrence frequency of crustacean zooplankton in Lake Fuxian

\begin{tabular}{|c|c|c|c|c|}
\hline 种类 & 分布范围 & $\begin{array}{c}\text { 出现率 } \\
(\%)\end{array}$ & $\begin{array}{l}\text { 密度范围 } \\
\text { (ind./L) }\end{array}$ & $\begin{array}{l}\text { 平均密度 } \\
\text { (ind./L) }\end{array}$ \\
\hline 桡足类 Copepoda & 全湖 & 98.2 & $0-289$ & $11.9 \pm 36.9$ \\
\hline $\begin{array}{l}\text { 舌状叶镖水蚤 } \\
\text { Phyllodiaptomus tunguidus Shen et Tai }\end{array}$ & 全湖 & 85.5 & $0-285.5$ & $11.4 \pm 36.4$ \\
\hline 剑水蚤 Cyclopoids & 全湖 & 74.5 & $0-4.5$ & $0.4 \pm 0.7$ \\
\hline 无节幼体 Nauplii & 全湖 & 91.8 & $0-148$ & $12.0 \pm 25.6$ \\
\hline 枝角类 Cladocera & 全湖 & 84.6 & $0-43$ & $3.7 \pm 6.7$ \\
\hline 角突网纹溞 Ceriodaphnia cornuta Sars & 全湖 & 69.1 & $0-39.5$ & $2.3 \pm 5.6$ \\
\hline 象鼻溞 Bosmina sp. & 全湖 & 72.7 & $0-26.3$ & $1.3 \pm 3.3$ \\
\hline 圆形盘肠溞 Chydorus sphaericus (O. F. Müller) & 隔河口附近 & 5.5 & $0-1.4$ & $0.022 \pm 0.140$ \\
\hline 长刺溞 Daphnia longispina (O. F. Müller) & 隔河附近 & 3.6 & $0-0.5$ & $0.008 \pm 0.052$ \\
\hline 矩形尖额溞 Alona rectangular Sars & 北岸西段 & 0.9 & 0.1 & $0.001 \pm 0.0095$ \\
\hline 秀体溞 Diaphanosoma sp. & 隔河口附近 & 0.9 & 0.1 & $0.001 \pm 0095$ \\
\hline
\end{tabular}

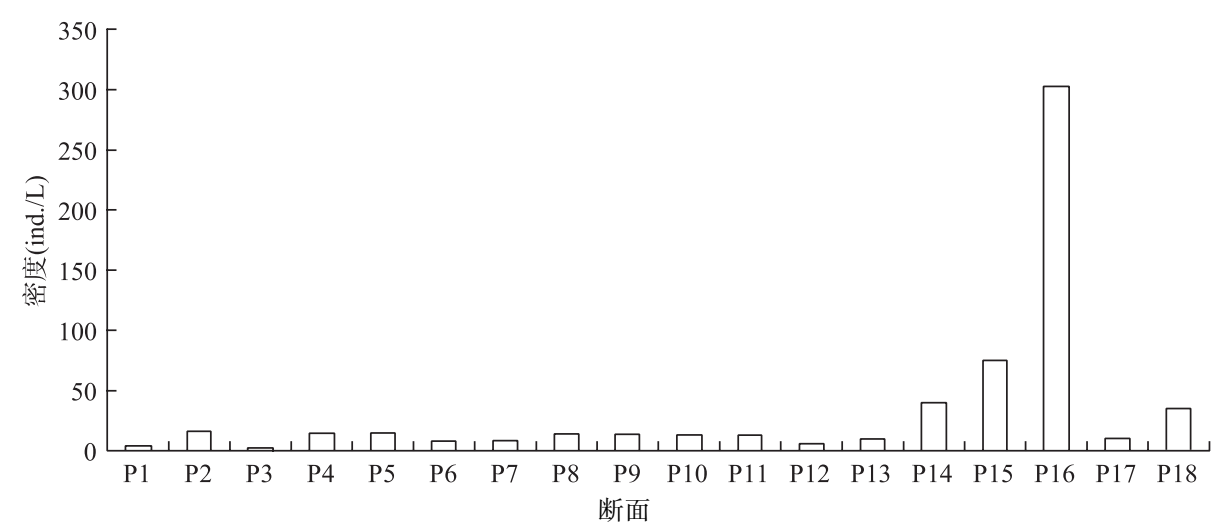

图 2 抚仙湖不同断面浮游甲壳动物的密度

Fig.2 Distribution in density of crustacean zooplankton in the sampling sections of Lake Fuxian

2.3.2 垂直分布 抚仙湖深水区浮游甲壳动物密度随水深的增加呈下降趋势(图 4), 主要分布在 0-30m 水 层, 约占整个水柱总数量的 $63.9 \%$. 在 0-10m 水层, 枝角类和无节幼体占优势, 平均密度为 9.7ind./L; 当 水深大于 $10 \mathrm{~m}$ 时, 桡足类占优势. 水深大于 $50 \mathrm{~m}$ 时, 浮游甲壳动物密度较低, 小于 2ind./L.

不同类群的密度垂直分布情况不同. 枝角类主要分布在 0-10m 水层中, 10-50m 水层密度较小, 平均 为 $0.59 \mathrm{ind} . / \mathrm{L}$, 大于 $50 \mathrm{~m}$ 时, 基本无分布. 桡足类在 $0-150 \mathrm{~m}$ 的水层中均有分布, 主要分布在 $10-30 \mathrm{~m}$ 水层, 当水深大于 $70 \mathrm{~m}$ 时, 密度较低, 平均为 $0.3 \mathrm{ind} . / \mathrm{L}$. 无节幼体在整个水层中均有分布, 主要分布在 $0-10 \mathrm{~m}$ 水层, 随水深增加, 密度下降很快, 当水深大于 $50 \mathrm{~m}$ 时, 平均密度仅 $0.27 \mathrm{ind} . / \mathrm{L}$. 

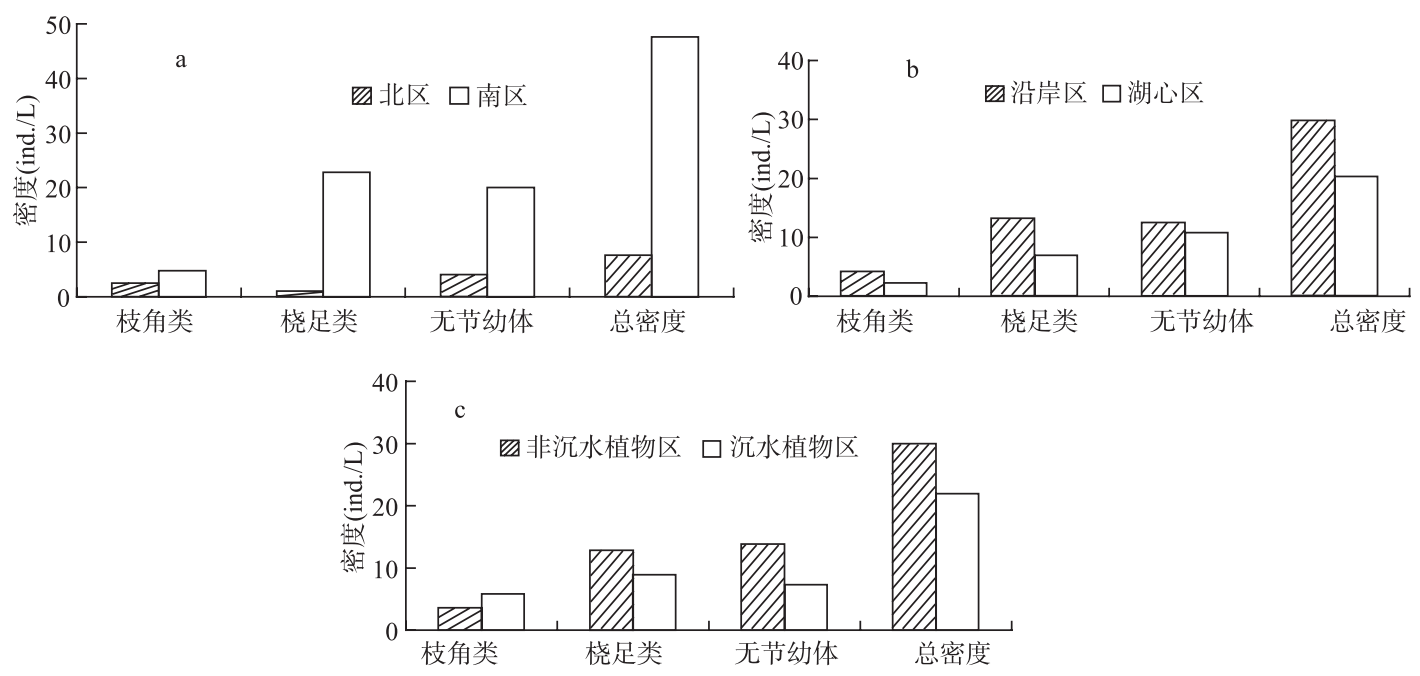

图 3 抚仙湖不同湖区浮游甲壳动物密度比较

(a: 南区与北区; b: 沿岸区与湖心区; c: 沉水植物区与非沉水植物区)

Fig.3 Comparison of crustacean zooplankton density in different regions of Lake Fuxian

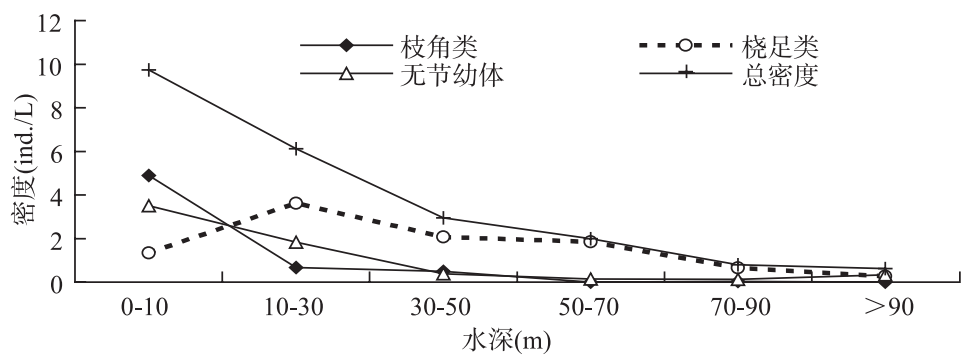

图 4 抚仙湖浮游甲壳动物密度的垂直分布

Fig.4 Vertical distribution in density of crustacean zooplankton in Lake Fuxian

\section{4 密度与环境因子的关系}

2.4.1 水平分布的影响因子 Pearson 相关分析表明, 在水平分布上, 浮游甲壳动物总密度、桡足类密度、 无节幼体密度与水深、总氮、溶解性总氮、总磷、溶解性总磷、叶绿素 $\mathrm{a}$ 、悬浮物、藻类密度等因子相 关关系均不显著 $(P>0.05)$, 而枝角类密度与总磷、溶解性总磷显著正相关 $(P<0.05)$ 、与叶绿素 a 极显著正 相关 $(P<0.01)$.

2.4.2 垂直分布的影响因子 在垂直分布上, 浮游甲壳动物密度与水深呈极显著负相关 $(P<0.01)$, 与藻类 密度、电导率、温度、 $\mathrm{pH}$ 值、叶绿素 $\mathrm{a}$ 、溶解氧、总氮、溶解性总氮、有效光合辐照等因子极显著正相 关 $(P<0.01)$, 而与总磷、溶解性总磷相关关系不显著 $(P>0.05)$. 枝角类、无节幼体与各环境因子的关系与 总密度的情况基本一致. 桡足类密度与电导率、温度、 $\mathrm{pH}$ 值显著相关 $(P<0.05)$, 与有效光合辐照、溶解 氧的相关关系不显著 $(P>0.05)$, 其它情况与总密度的基本一致.

\section{3 分析与讨论}

\section{1 群落结构与分布特征}

抚仙湖所处纬度虽然较低, 但因位于高原, 气候并不炎热, 浮游动物组成中除角突网纹溞为嗜暖性 
种类外, 多数为广温性种类, 分布较广. 抚仙湖 6-7 月浮游甲壳动物群落以桡足类为优势类群, 桡足类及 其幼体约占浮游甲壳动物总量的 $87 \%$. 此外, 各类群优势种的优势度也很高, 如桡足类中舌状叶镖水蚤 占了 $96.2 \%$, 枝角类中角突网纹溞和象鼻溞占了 $99.2 \%$. 一般认为, 浮游甲壳动物密度与水体营养水平呈 正相关 ${ }^{[5,8]}$. 抚仙湖浮游甲壳动物平均密度为 $27.6 \mathrm{ind}$./L, 略高于大型深水水库, 如新丰江水库约为 10.6ind./L $\mathrm{L}^{[1]}$, 千岛湖为 13.85ind./[ ${ }^{[19]}$, 但远低于富营养化严重的浅水湖泊, 如广东星湖为 $41.27 \mathrm{ind} . / \mathrm{L}^{[20]}$, 太湖梅梁湾为 214ind./ $\mathrm{L}^{[10]}$. 这种密度较低的特点一方面与抚仙湖所处贫营养状态有关, 另一方面可能与 浮游动物食性鱼类的摄食压力有关. 高密度的浮游动物食性鱼类往往造成浮游甲壳动物的贫 ${ }^{[11-22]}$. 在 太湖, 鲚对浮游动物产生了巨大的摄食压力 ${ }^{[23]}$; 在洱海, 太湖新银鱼形成稳定优势种群后, 在长期的高 摄食压力下, 枝角类和桡足类密度分别由 1980 年的 80ind./L 和 155ind./L 减小到 1997 年的 5.4ind./L 和 8.7ind./L $\mathrm{L}^{[24]}$. 抚仙湖鱼类优势种群一一太湖新银鱼以桡足类和枝角类为主要食物 ${ }^{[25]}, 1990-2004$ 年其平均 产量达 $1554 \mathrm{t}^{[16]}$, 对浮游甲壳动物的摄食压力显而易见.

抚仙湖浮游甲壳动物密度分布的显著特点是南区大于北区. 抚仙湖常年盛行西南风, 北部湖区比较 开敞, 风浪较大, 对浮游甲壳动物的栖息不利, 而南部湖区风浪相对较小, 特别是在南部湖湾, 水体平静, 适合浮游甲壳动物的栖息. 此外, 受富营养化湖泊星云湖来水影响, 抚仙湖滆河口一带水体营养水平较 高, 增加了浮游甲壳动物的种类和密度, 如盘肠溞、溞、秀体溞等主要在这一区域出现. 从垂直分布看, 抚仙湖深水区浮游甲壳动物主要分布在 0-30m 水层中, 这与其水温的垂直分布一致, 抚仙湖 7 月份增温 的水层在 $45 \mathrm{~m}$ 以内 ${ }^{[12]}$. 但采样发现, $30 \mathrm{~m}$ 以下的水层中, 浮游甲壳动物仍有一定的分布, 特别是深水层桡 足类较多, 在 $150 \mathrm{~m}$ 深处, 无节幼体的密度也能达到 $2.5 \mathrm{ind} . / \mathrm{L}$, 这可能与浮游甲壳动物的沉降有关系. 综 合 Pearson 相关分析的结果: 浮游甲壳动物密度的垂直分布与藻类密度和水体理化因子相关关系显著, 而 水平分布与藻类密度和水体理化因子相关关系不显著.

\section{2 密度变化与优势种演替}

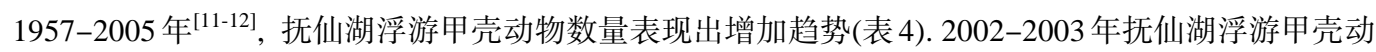
物的周年样中 4 月密度为最大值, 7 月基本接近最小值 ${ }^{[25]}$, 本次调查结果为 2003 年同期的 11 倍多, 且高 于 2003 年 4 月的密度. 这种密度增加趋势与抗仙湖营养水平及藻类密度的增加有关.

表 4 1957-2005 年抚仙湖浮游甲壳动物的密度变化

Tab.4 Long-term changes in density of crustacean zooplankton of Lake Fuxian during 1957-2005

\begin{tabular}{|c|c|c|c|c|c|c|}
\hline 年 & 月 & 枝角类(ind./L) & 桡足类(ind./L) & 无节幼体(ind./L) & 总密度(ind./L) & 参考资料 \\
\hline 1957 & $7-10$ & 1.0 & $<20$ & - & - & [11] \\
\hline 1980 & 4 & 1.9 & 10.5 & - & 12.4 & [12] \\
\hline 2003 & 4 & 9.83 & 8.69 & 3.64 & 24.81 & [25] \\
\hline 2003 & 7 & - & - & - & $<2.50$ & [25] \\
\hline 2005 & 7 & 3.69 & 11.90 & 12.02 & 27.61 & 本研究 \\
\hline
\end{tabular}

与 1980 年相比 ${ }^{[12]}$, 抚仙湖浮游甲壳动物群落结构的一个显著变化是桡足类优势种由西南荡镖水蚤 (Neutrodiaptomus mariadviagae mariadviagae (Brohm))演替为舌状叶镖水虫, 且西南荡镖水蚤已经消失. 在 滇池, 太湖新银鱼主要捕食西南荡镖水蚤, 导致其密度明显下降 ${ }^{[26]}$. 在洱海, 太湖新银鱼引人后西南荡镖 水蚤的优势地位丧失，枝角类和桡足类没有明显的优势种 ${ }^{[24]}$. 抚仙湖西南荡镖水蚤的消失很可能是基于太 湖新银鱼强大的捕食压力. 一般认为太湖新银鱼对浮游动物有选择性, 浮游动物个体越大, 选择系数越高, 对桡足类的选择性大于枝角类, 对枝角类中象鼻溞的选择性很小 ${ }^{[27]}$. 而在抚仙湖中, 太湖新银鱼对小型枝 角类象鼻溞有较高的选择性，而对桡足类的优势种舌状叶镖水蚤选择性并不高 ${ }^{[25]}$. 鱼类捕食浮游动物的选 择性与浮游动物的种类和逃避能力有关, 浮游动物食性鱼类的捕食会促使具有较强逃避能力的种类占优势 [21]. 可能舌状叶镖水蚤逃避捕食的能力要强于西南荡镖水蚤, 从而使其能够保持一定的种群密度, 成为优 势种. 枝角类的运动能力差于桡足类, 在食物缺乏的情况, 太湖新银鱼选择了枝角类. 20 世纪 80 年代初太 
湖新银鱼进人抚仙湖之前, 湖中并未有舌状叶镖水蚤的记录 ${ }^{[11-12]}$, 关于舌状叶镖水蚤的来源, 可能由与之 相通的星云湖进人. 对抚仙湖浮游甲壳动物的长期演变过程还需要深人研究和长期监测.

\section{4 参考文献}

[1] 赵帅营, 韩博平. 大型深水贫营养水库——新丰江水库浮游动物群落分析. 湖泊科学, 2007, 19(3): 305-314.

[2] Wissel B, Ramacharan CW. Plasticity of vertical distribution of crustacean zooplankton in lakes with varying levels of water color. J Plankton Res, 2003, 25(9): 1047-1057.

[3] Chang KH, Hanazato T. Seasonal and spatial distribution of two Bosmina species (B. longirostris and B. fatalis) in Lake Suwa, Japan: its relation to the predator Leptodora. Limnology, 2003, 4(1): 47-52.

[4] Xie P, Yang Y. Long-term changes of Copepoda community (1957-1996) in a subtrophic Chinese lake stocked densely with planktivorous filter-feeding silver and bighead carp. J Plankton Res, 2000, 22(9): 1757-1778.

[5] Pinto-Coelho R, Pinel-Alloul B, Méthot G et al. Crustacean zooplankton in lakes and reservoirs of temperate and tropical regions: variation with tropic status. Can J Fish Aquat Sci, 2005, 62(2): 348-361.

[6] Løvik JE, Kjellberg G. Long-term changes of the crustacean zooplankton community in Lake Mjøsa, the largest lake in Norway. Journal of Limnology, 2003, 62(2): 143-150.

[7] Larson GL, McIntire CD, Buktenica MW et al. Distribution and abundance of zooplankton populations in Crater Lake, Oregon. Hydrobiologia, 2007, 574(1): 217-233.

[8] 鲁 敏, 谢 平. 武汉东湖不同湖区浮游甲壳动物. 海洋与湖沼, 2002, 33(2): 174-181.

[9] Deng DG, Xie P, Zhou Q et al. Field and experimental studies on the combined impacts of cyanobacterial blooms and small algae on crustacean zooplankton in a large, eutrophic, subtropical, Chinese lake. Limnology, 2008, 9(1): 1-11.

[10] 杨桂军, 潘宏凯, 刘正文等. 太湖不同湖区浮游甲壳动物季节变化的比较. 中国环境科学, 2008, 28(1): 27-32.

[11] 黎尚豪, 俞敏娟, 李光正等. 云南高原湖泊调查. 海洋与湖沼, 1963, 5(2): 100-110.

[12] 中国科学院南京地理与湖泊研究所. 抚仙湖. 北京: 海洋出版社, 1990.

[13] 潘继征, 熊飞, 李文朝等. 云南抚仙湖透明度的时空变化及影响因子分析. 湖泊科学, 2008, 20(5): 681-686.

[14] 李荫坌, 王 林, 祁云宽等. 抚仙湖浮游植物发展趋势分析. 湖泊科学, 2007, 19(2): 223-226.

[15] Zhang X, Xie P, Chen FZ et al. Present status and changes of the phytoplankton community after invasion of Neosalanx taihuensis since 1982 in a deep oligotrophic plateau lake, Lake Fuxian in the subtrophic China. Journal of Environmental Sciences, 2005, 17(3): 389-394.

[16] 熊 飞, 李文朝, 潘继征等. 云南抚仙湖鱼类资源现状与变化. 湖泊科学, 2006, 18(3): 305-311.

[17] 章宗涉, 黄祥飞. 淡水浮游生物研究方法. 北京: 科学出版社, 1991.

[18] 水和废水监测分析方法编委会. 水和废水监测分析方法(第四版). 北京: 中国环境科学出版社, 2002.

[19] 盖建军, 王丽卿, 刘其根等. 千岛湖浮游甲壳类群落结构特征初步研究. 上海水产大学学报, 2007, 16(6): 560-565.

[20] 赵帅营, 林秋奇, 刘正文等. 南亚热带湖泊一星湖后生浮游动物群落特征研究. 水生生物学报, 2007, 31(3): 405-413.

[21] Lazzaro X. A review of planktivorous fishes: their evolution, feeding behaviors, selectivities and impacts. Hydrobiologica, 1987, 146: 97-167.

[22] Reynolds CS. The ecological basis for the successful biomanipulation of aquatic communities. Arch Hydrobiol, 1994, 130(1): $1-33$.

[23] 刘恩生, 吴林坤, 曹 萍等. 太湖鱼类渔获量和优势种年龄组成的变化规律及其下行效应分析. 安徽农业大学学报, 2005, 32(4): 471-477.

[24] 吴庆龙, 王云飞. 洱海生物群落的历史演变分析. 湖泊科学, 1999, 11(3): 267-273.

[25] 覃剑晖. 太湖新银鱼人侵高原深水贫营养湖泊——抚仙湖的生态学效应. 武汉: 中国科学院水生生物研究所, 2005.

[26] 刘正文, 朱松泉. 滇池产太湖新银鱼食性与摄食行为的初步研究. 动物学报, 1994, 40(3): 253-261.

[27] 尤 洋, 尤 琦, 郭祖峰等. 不同纬度太湖新银鱼的食性比较及其饵料生物学容量评价. 西南民族学院学报(自然科学 版), 1999, 25(2): 176-180. 